\title{
Fourier transform infrared and near-infrared spectroscopic methods for the detection of toxic Diethylene Glycol (DEG) contaminant in glycerin based cough syrup
}

\author{
M. Khalique Ahmed ${ }^{\mathrm{a}, *}$, Michael P. McLeod ${ }^{\mathrm{b}}$, Jean Nézivar ${ }^{\mathrm{a}}$ and Allison W. Giuliani ${ }^{\mathrm{c}}$ \\ ${ }^{a}$ Department of Science, College of Liberal Education, Lynn University, North Military Trail, \\ Boca Raton, FL, USA \\ ${ }^{\mathrm{b}}$ University of Miami, Miller School of Medicine at Florida Atlantic University, Boca Raton, FL, USA \\ ${ }^{\mathrm{c}}$ Department of Biological Sciences, Florida Atlantic University, Boca Raton, FL, USA
}

\begin{abstract}
Recently there have been reports of the contamination of cough syrups with Diethylene Glycol (DEG). The consumption of such cough syrups has devastating effects on the health. In this paper we report evidence that Fourier transform infrared (FT-IR) and near-infrared (NIR) spectroscopic techniques are viable, simple, cost effective, rapid and fool proof methods for the identification and quantification of DEG in glycerin based cough syrups. The FT-IR and NIR spectra of the glycerin based cough syrup and up to 50:50 mixtures of DEG in cough syrup are recorded. The major peaks in the FT-IR spectrum of the cough syrup are assigned to the $\mathrm{OH}$ stretching $\left(\sim 3300 \mathrm{~cm}^{-1}\right)$, CH stretching $\left(\sim 2900 \mathrm{~cm}^{-1}\right), \mathrm{CH}$ bending $\left(1500-1200 \mathrm{~cm}^{-1}\right)$ and $\mathrm{C}-\mathrm{O}$ stretching $\left(1200-900 \mathrm{~cm}^{-1}\right)$ vibrational modes. In the FT-IR spectra of the mixtures, DEG contribute distinct peaks due to the vibrations of the $\mathrm{C}-\mathrm{O}\left(920 \mathrm{~cm}^{-1}\right)$ and $\mathrm{OC}_{2} \mathrm{H}_{4}\left(892 \mathrm{~cm}^{-1}\right)$ moieties of its backbone and form the basis of the DEG detection and quantification. The prominent peaks of the NIR spectra of cough syrup and DEG are assigned to the first overtones of $\mathrm{OH}$ and $\mathrm{CH}$, and to the combination of $\mathrm{OH}$ and $\mathrm{CH}$ fundamental vibrations. Both FT-IR and NIR Partial Least Square (PLS) calibrations produced correlation coefficients of 0.98 .
\end{abstract}

Keywords: Infrared spectroscopy, near-infrared spectroscopy, cough syrup, diethylene glycol, contaminant, detection

\section{Introduction}

Diethylene Glycol (DEG) is an inexpensive, sweet tasting [1-3], industrial solvent commonly used in antifreeze solutions [1,4]. It is often substituted for more expensive chemicals $[1,4]$ such as glycerin and propylene glycol $[3,6]$ in pharmaceutical products such as tooth paste, injectable drugs, fever medication and cough syrup [8]. DEG has a molecular weight of $106.12 \mathrm{~g} / \mathrm{mol}$, a boiling point of $245^{\circ} \mathrm{C}$, a melting point of $-6.5^{\circ} \mathrm{C}$ and a vapor pressure of $<0.01 \mathrm{mmHg}$ at $25^{\circ} \mathrm{C}$ [8]. It has been implicated in a number of serious world-wide contaminations with devastating human consequences; the first well documented case being the Massergil Tragedy of 1937 in the United States [5,6,9]. This tragedy was the stimulus behind passing the 1938 Federal Food, Drug and Cosmetic Act requiring product safety before being marketed [8,9]. Most recently in December 2008, Cable News Network (CNN) reported

\footnotetext{
${ }^{*}$ Corresponding author: M. Khalique Ahmed, Department of Science, College of Liberal Education, Lynn University, 3601 North Military Trail, Boca Raton, FL 33431, USA.
} 
dozens of children deaths in Nigeria due to DEG poisoning. The symptoms of DEG poisoning include acute renal failure $[1,3,5,6,10]$, metabolic acidosis $[1,5,6]$, diarrhea $[1,6]$, vomiting $[1,3,6]$, and delayed (1-2 weeks post ingestion) neurotoxicity [4,9], i.e., optic neuritis, demyelination of peripheral and cranial nerves, and cerebral atrophy. The minimum toxic dose is not readily agreed upon; however, the median toxic dose for DEG has been reported to be $1.34 \mathrm{ml} / \mathrm{kg}$ with a range from $0.22-4.42 \mathrm{ml} / \mathrm{kg}$ [7]. DEG has been postulated to be toxic when converted by alcohol and aldehyde dehydrogenases to 2-hydroxyethoxyacetic acid (HEAA) [5,11]. DEG poisoning is best treated when discovered early [12$15]$ in the pathogenesis by implementing the alcohol dehydrogenase inhibitor fomepizole [3,5], ethanol infusion [2,15] and hemodialysis [3].

In the current study, we report evidence that FT-IR and NIR spectroscopic techniques are viable screening tools in the identification and quantification of DEG in glycerin based cough syrup.

\section{Experimental section}

Samples: Glycerin based Robitussin cough syrup was purchased from the local pharmacy. Active ingredient of the syrup was dextromethorphan $\operatorname{HBr}(15 \mathrm{mg} / 5.0 \mathrm{ml})$ and the major inactive ingredients were glycerin and water. The DEG was purchased from Sigma Aldrich and had the stated purity of $99 \%$. The glycerin of $99 \%$ purity was purchased from the Fisher Scientific. The cough syrup was spiked with known amounts of DEG ranging from 3 to 50\% DEG. The resultant samples were vortexed to perform infrared and near-infrared spectroscopic measurements.

FT-IR spectra: FT-IR spectra were recorded on a Bruker Vector 33 spectrometer equipped with a $\mathrm{KBr}$ beam splitter and deuterated triglycine sulfate (DTGS) room temperature detector. The spectra were recorded in the attenuated total reflection (ATR) mode with a single bounce MIRacle ${ }^{\circledR}$ ATR accessory from PIKE technologies, Inc. (Madison, WI, USA). The accessory was equipped with a split pea shaped ZnSe ATR crystal. To record spectra, about $10 \mu \mathrm{l}$ of sample solution was poured on the ATR crystal and the single beam spectrum was recorded and then was rationed against the single beam spectrum of the bare crystal to obtain the absorbance spectrum. Spectra were recorded with a resolution of $4 \mathrm{~cm}^{-1}$ and 64 scans were averaged for each spectrum. The spectrometer's optics were sealed from the atmosphere but its compartment was not purged during measurements.

NIR spectra: The near-infrared spectra were recorded in the absorbance mode using $1 \mathrm{~mm}$ rectangular quartz cell. The instrument (Bruker Vector 33) was equipped with the tungsten source, $\mathrm{CaF}_{2}$ beam splitter and the germanium detector. The spectra were run at the resolution of $4 \mathrm{~cm}^{-1}$ and for each spectrum 64 scans were averaged.

Data processing: The spectra were run and processed with the Bruker OPUS (Optical User Software) program. The recorded infrared and near-infrared spectra were subjected to the Partial Least Squares (PLS) analysis using QUANT program of the Bruker Instruments. The procedure produced the actual and predicted values of DEG in cough syrup.

\section{Results and discussion}

FT-IR spectra: The infrared spectra of glycerin based cough syrup and of DEG are shown in Fig. 1. The spectrum of cough syrup is dominated by peaks due to water and glycerin. The band at $3300 \mathrm{~cm}^{-1}$ is due to $\mathrm{OH}$ stretching modes of water and glycerin whereas the band at $1650 \mathrm{~cm}^{-1}$ is mainly due to $\mathrm{OH}$ bending mode of water. The other peaks of the cough syrup are mainly due to the presence of glycerin. The peaks around $2900 \mathrm{~cm}^{-1}$ are due to the $\mathrm{CH}$ stretching modes of glycerin whereas the peaks between 


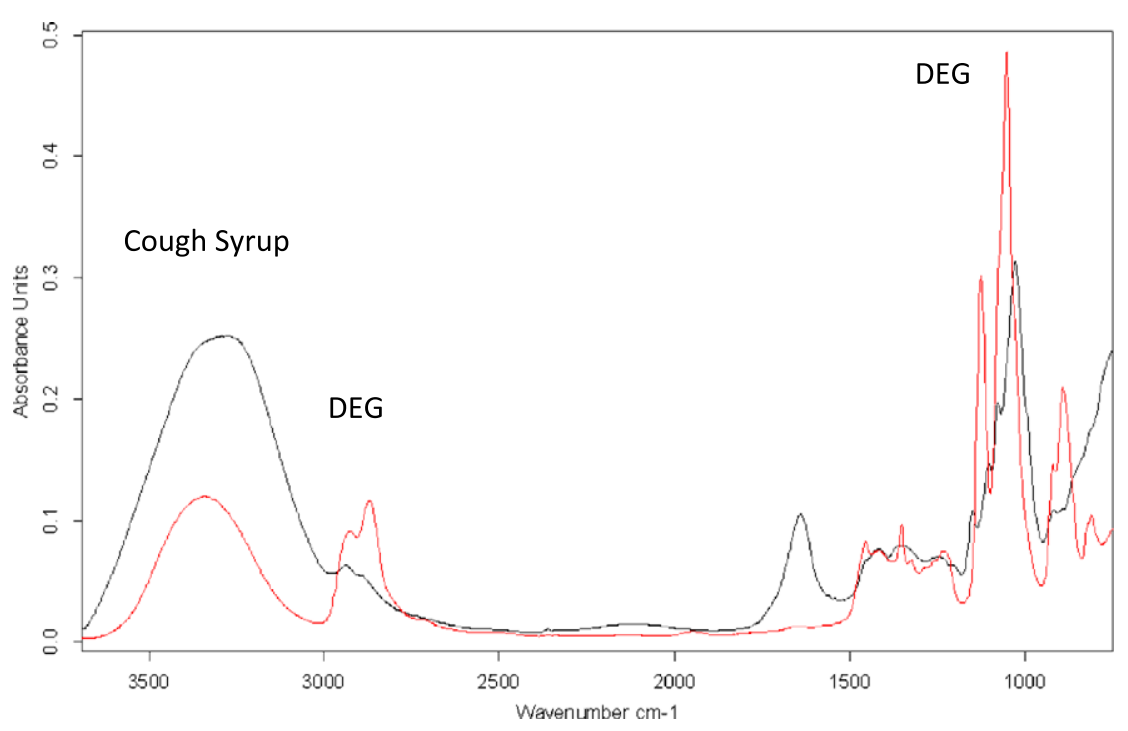

Fig. 1. Infrared spectra of glycerin based cough syrup and diethylene glycol. (The colors are visible in the online version of the article; http://dx.doi.org/10.3233/SPE-2010-0482.)

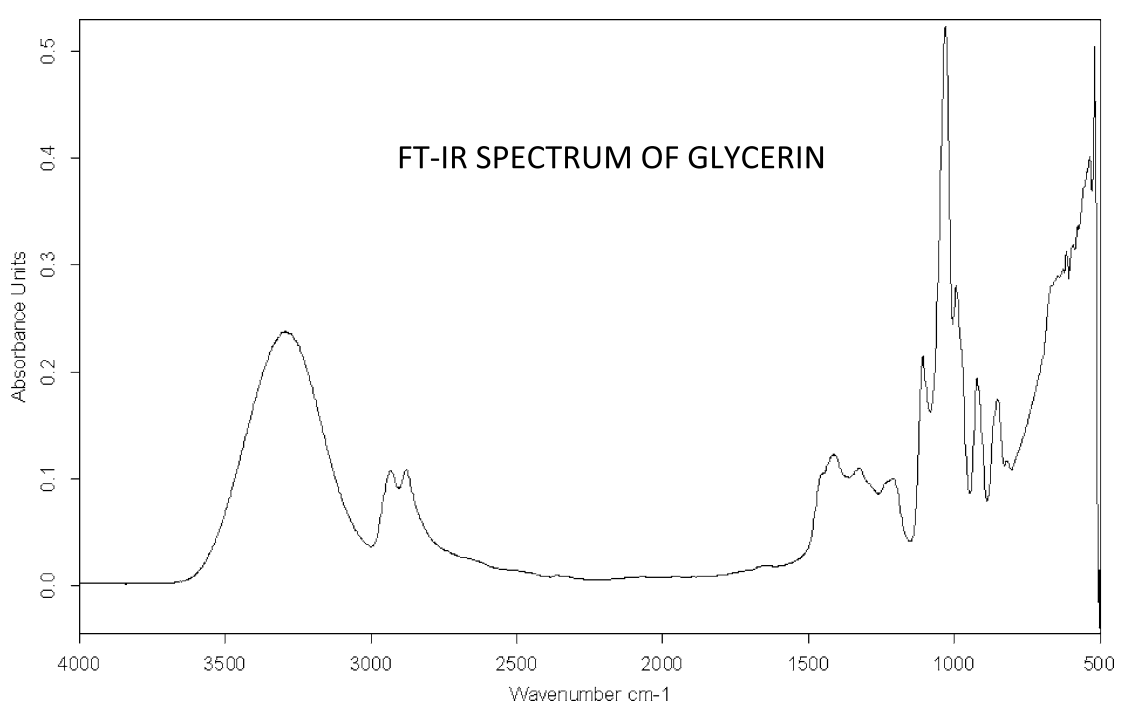

Fig. 2. Infrared spectrum of glycerin.

$1500-700 \mathrm{~cm}^{-1}$ are due to $\mathrm{CH}$ bending $\left(1500-1200 \mathrm{~cm}^{-1}\right)$ and C-O stretching $\left(1200-900 \mathrm{~cm}^{-1}\right)$ modes of glycerin. The glycerin peaks in cough syrup were confirmed by running the spectrum of pure glycerin that is shown in Fig. 2. The assignments of the FT-IR spectra of the cough syrup, glycerin and DEG are given in Table 1. The closer inspection of the spectra of Fig. 1 revealed absorptions in the region of $930-870 \mathrm{~cm}^{-1}$ in the DEG spectrum that are absent in the cough syrup spectrum. These absorptions are possibly from the $\mathrm{C}-\mathrm{O}\left(920 \mathrm{~cm}^{-1}\right)$ and $\mathrm{OC}_{2} \mathrm{H}_{4}\left(892 \mathrm{~cm}^{-1}\right)$ moieties of the backbone of DEG. This assignment is reasonable as glycerin does not have $\mathrm{OC}_{2} \mathrm{H}_{4}$ moiety and that is why $892 \mathrm{~cm}^{-1}$ absorption is absent in the cough syrup. The $930-870 \mathrm{~cm}^{-1}$ region peaks of DEG were used for the quantization of DEG in cough syrup through Partial Least Squares (PLS) procedure. Figure 3 shows the sensitivity 
Table 1

Assignments of the infrared spectra of the cough syrup, Diethylene Glycol (DEG) and glycerin. Peak positions are in wavenumbers $\left(\mathrm{cm}^{-1}\right)$

\begin{tabular}{lcll}
\hline Cough syrup & DEG & Glycerin & \multicolumn{1}{c}{ Assignment } \\
\hline 3306 & 3340 & 3295 & $\mathrm{OH}$ stretch \\
2938 & 2924 & 2932 & $\mathrm{CH}_{2}$ antisym. stretch \\
2890 & 2870 & 2879 & $\mathrm{CH}_{2}$ sym. stretch \\
1639 & $\ldots$ & $\ldots$ & $\mathrm{OH}$ bending \\
1420 & 1455,1419 & 1412 & $\mathrm{CH}_{2}$ bending \\
1356 & 1362,1324 & 1326 & $\mathrm{CH}_{2}$ wagging \\
1150 & 1234 & 1209 & $\mathrm{CCC}, \mathrm{COC}$ stretch \\
1104 & 1125 & 1108 & $\mathrm{C}-\mathrm{O}$ stretch \\
1077 & 1062 & 1030 & $\mathrm{C}-\mathrm{O}$ stretch \\
1028 & 920 & 993,922 & $\mathrm{COH}$ stretch \\
$\ldots$ & 892 & $\ldots$ & $-\mathrm{OC}_{2} \mathrm{H}_{4}$ \\
\hline
\end{tabular}

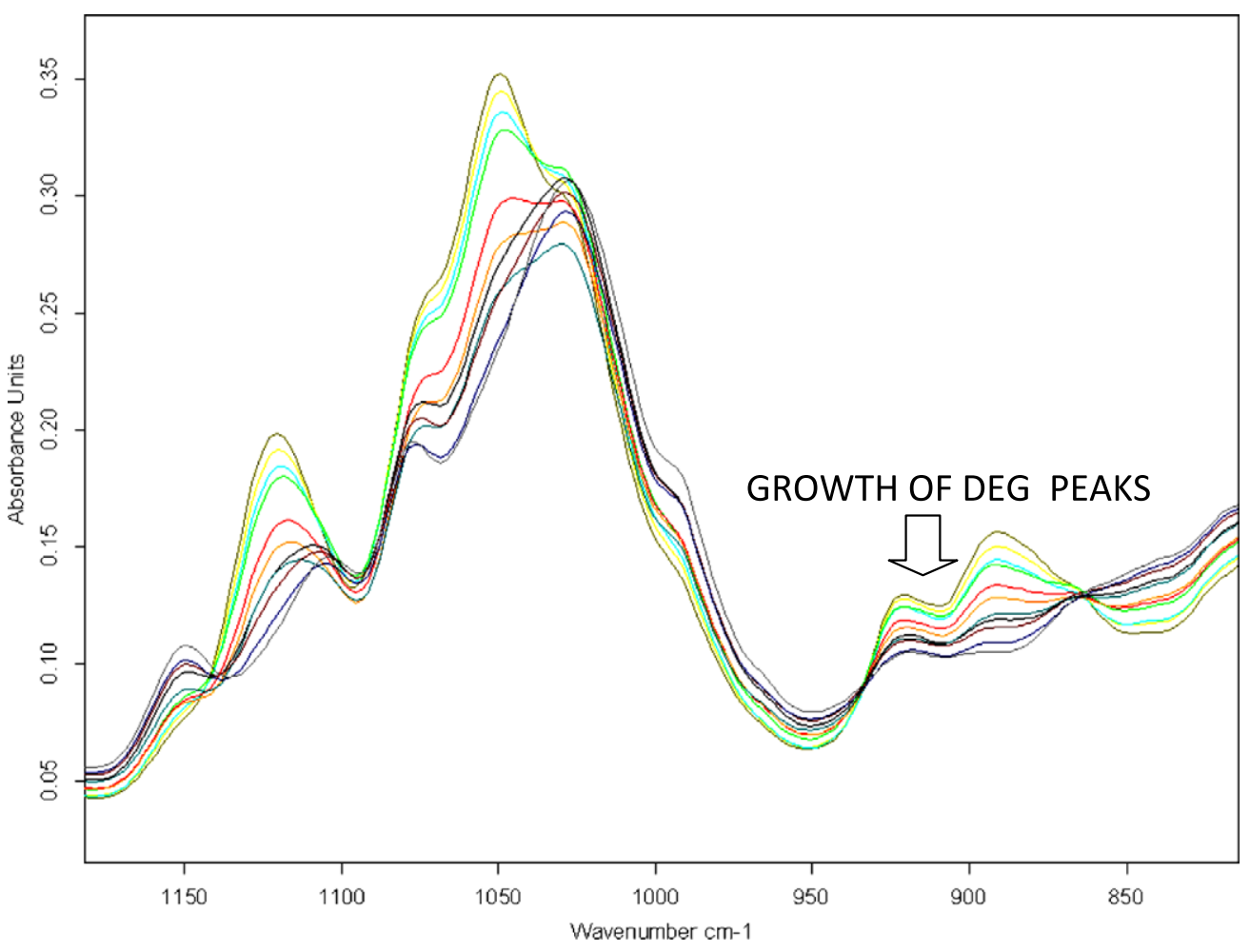

Fig. 3. The infrared spectra showing the sensitivity of the contaminated cough syrup to the presence of varying amounts $(0-50 \%)$ of diethylene glycol. (The colors are visible in the online version of the article; http://dx.doi.org/10.3233/SPE-2010-0482.)

of the FT-IR spectra of the contaminated cough syrups to the presence of varying amounts of DEG. As can be seen the $930-870 \mathrm{~cm}^{-1}$ peaks grow linearly with the concentration of DEG in cough syrup. The plot of PLS predicted and actual values of DEG from FT-IR spectra is shown in Fig. 4. The agreement between predicted and actual values is excellent.

NIR spectra: The near-infrared spectra of DEG and the cough syrup are shown in Fig. 5. In both spectra the bands between 5500-6000 and $6500-7000 \mathrm{~cm}^{-1}$ regions are due to first overtone of $\mathrm{CH}$ 


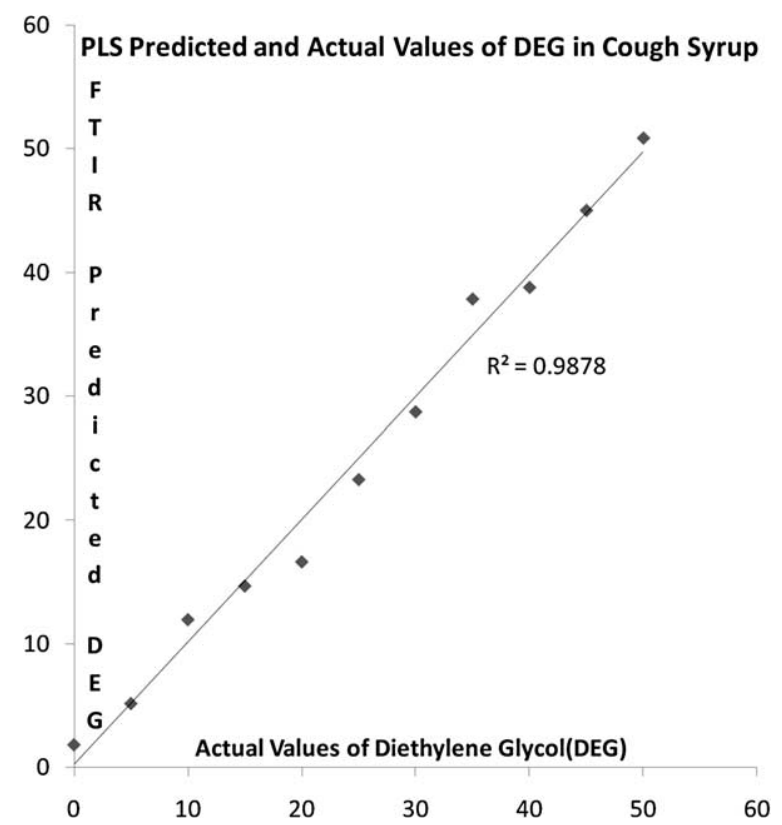

Fig. 4. Plot of the actual and predicted values of diethylene glycol in cough syrup from infrared spectroscopy.

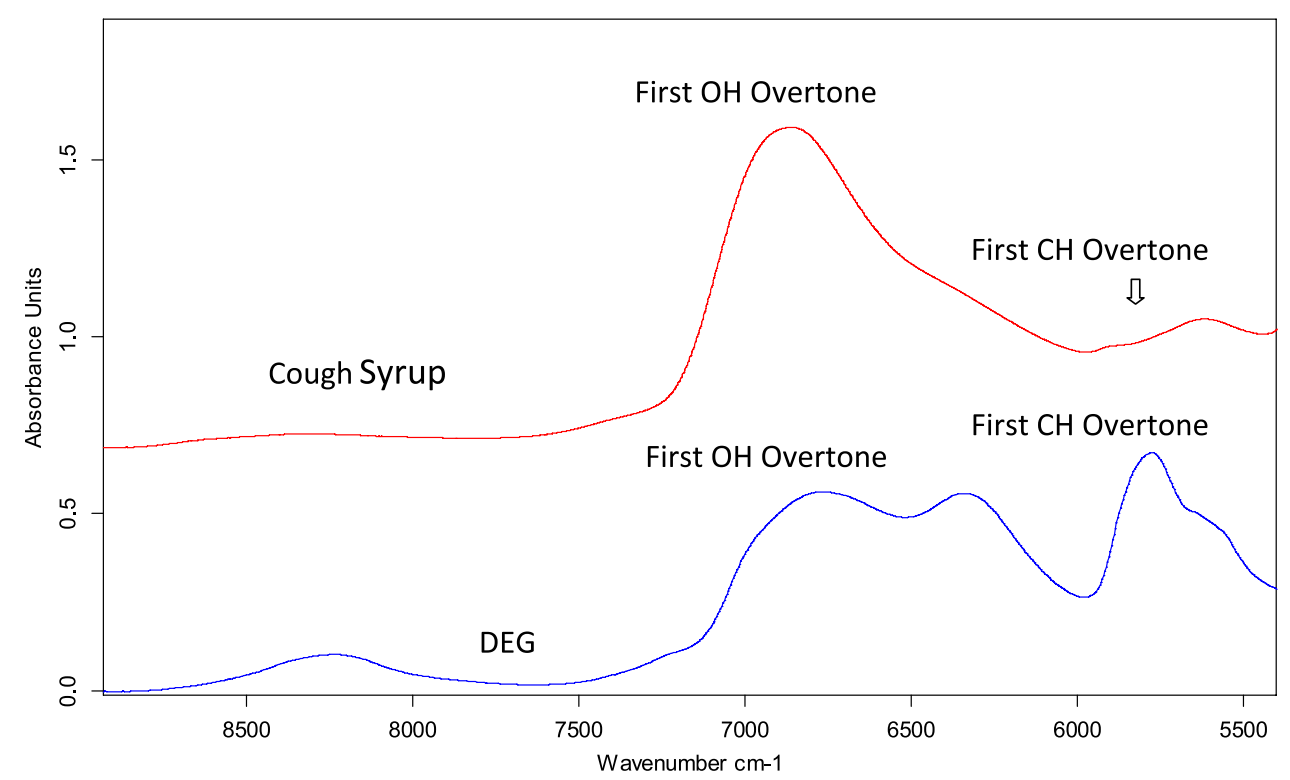

Fig. 5. Near-infrared spectra of a typical glycerin based cough syrup and diethylene glycol. (The colors are visible in the online version of the article; http://dx.doi.org/10.3233/SPE-2010-0482.)

and $\mathrm{OH}$ stretching vibrations, respectively. As can be seen in Fig. 5 DEG has distinct absorptions in the regions of $6000-5500 \mathrm{~cm}^{-1}$ whereas cough syrup absorbs very weakly in this region. The assignments of the NIR spectra of the cough syrup and DEG are given in Table 2. Figure 6 displays the sensitivity of the near-infrared spectra of the cough syrup to the presence of DEG. Because of the mutually exclusive 
Table 2

Assignments of the near-infrared spectra of the cough syrup and diethylene glycol

\begin{tabular}{ll}
\hline Frequency $\left(\mathrm{cm}^{-1}\right)$ & Assignment \\
\hline Cough syrup & \\
5630 & First $\mathrm{CH}$ (glycerin) overtone \\
$\sim 6350$ & $\mathrm{CH}$ stretch $+\mathrm{OH}$ stretch \\
6855 & First OH overtone \\
Diethylene glycol & \\
$\sim 5625$ & First $\mathrm{CH}$ overtone \\
5777 & First $\mathrm{CH}$ overtone \\
6347 & $\mathrm{CH}$ stretch + OH stretch \\
6772 & First OH overtone \\
8244 & Second $\mathrm{CH}$ overtone \\
\hline
\end{tabular}

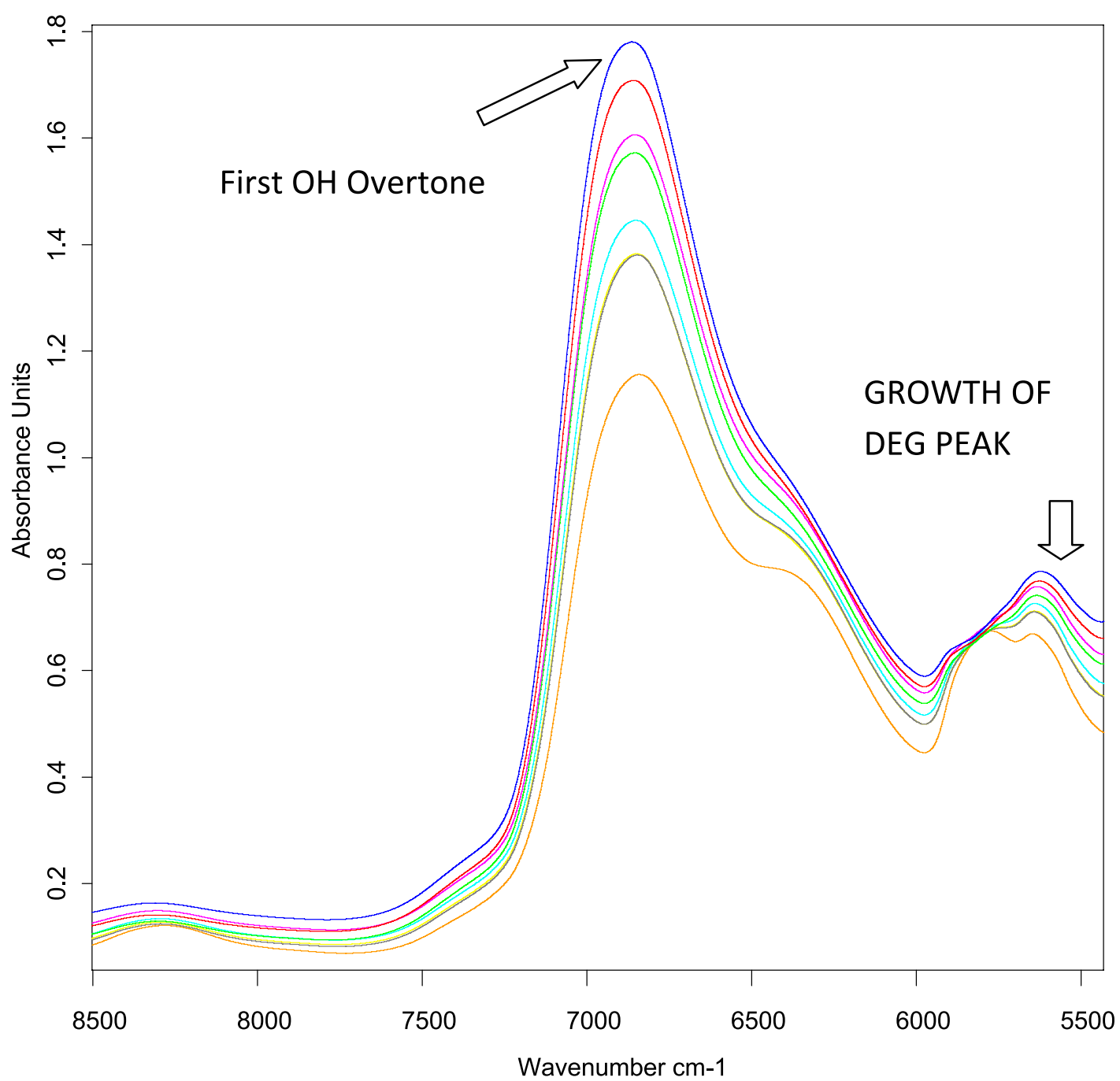

Fig. 6. Near-infrared spectra showing the sensitivity of the contaminated cough syrup to the presence of varying amounts (5-50\%) of diethylene glycol. (Colors are visible in the online version of the article; http://dx.doi.org/10.3233/SPE-2010-0482.) 


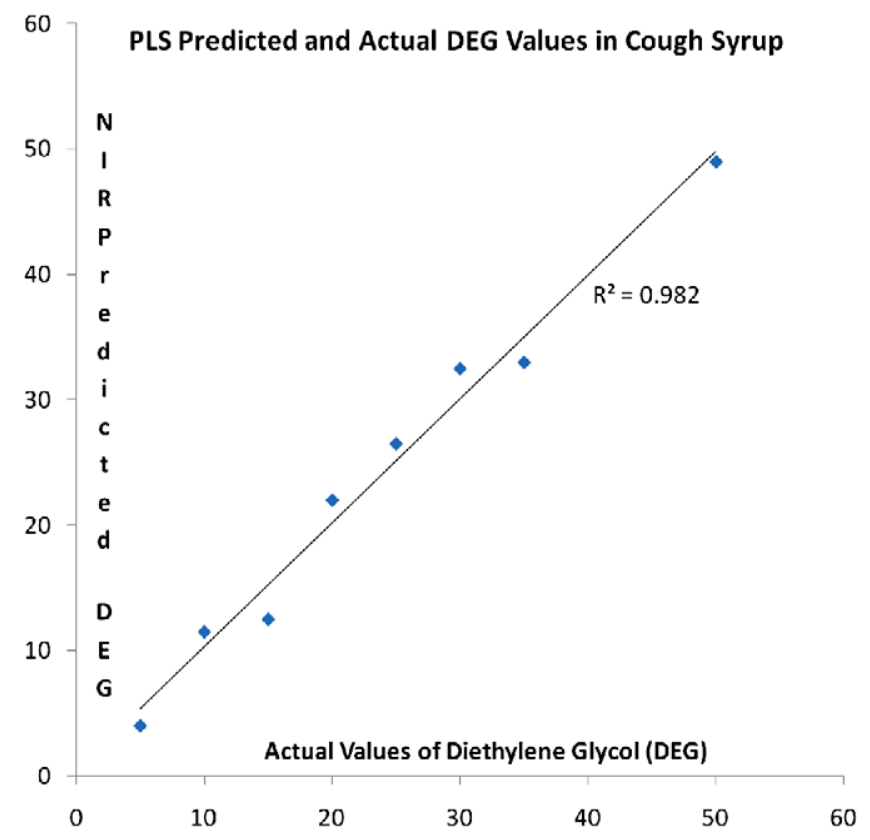

Fig. 7. Plot of the actual and predicted values of diethylene glycol in cough syrup from near-infrared spectroscopy. (Colors are visible in the online version of the article; http://dx.doi.org/10.3233/SPE-2010-0482.)

nature of the $6000-5500 \mathrm{~cm}^{-1}$ spectral range, this region was used in the determination of the DEG in the cough syrup.

The predicted and actual values of DEG from the near-infrared spectra are shown in Fig. 7 and display reasonable agreement.

\section{Conclusion}

The presence of toxic diethylene glycol (DEG) can be successfully detected and quantified in the glycerin based cough syrup by using FT-IR and NIR spectroscopic techniques. It should be noted that although FTIR and NIR techniques are not as sensitive as other analytical techniques such as mass spectrometry and high pressure liquid chromatography (15) but they have the advantage of being rapid and cost effective. Both FT-IR and NIR are well suited for the initial screening of the cough syrups before using the most sensitive analytical techniques. The FT-IR and NIR methods are environmentally friendly as they do not utilize any chemicals. The developed methods are especially suited for the third world where advanced lab facilities are uncommon and are the regions where most cases of the cough syrup contaminations have been reported.

\section{References}

[1] S. Alfred, P. Coleman, D. Harris, T. Wigmore, E. Stachowski and A. Graudins, Delayed neurologic sequelae resulting from epidemic diethylene glycol poisoning, Clinical Toxicology 43(3) (2005), 155-159.

[2] B.D. Barr, J.R. Barr, G. Weerasekera, J. Wamsley, S.R. Kalb, A. Sjodin et al., Identification and quantification of diethylene glycol in pharmaceuticals implicated in poisoning epidemics: an historical laboratory perspective, Journal of Analytical Toxicology 31 (2007), 295-303. 
[3] L.A. Ferrari and L. Giannuzzi, Clinical parameters, postmortem analysis and estimation of lethal dose in victims of a massive intoxication with diethylene glycol, Forensic Science International 153 (2005), 45-51.

[4] M.T. Gomes, M.I. Veríssimo and J.A. Oliveira, A new method for monitoring the contamination of glycerol with diethylene glycol, Journal of Pharmacy and Pharmacology 51 (1999), 233-236.

[5] P. Hari, Y. Jain and S.K. Kabra, Fatal encephalopathy and renal failure caused by diethylene glycol poisoning, Journal of Tropical Pediatrics 52(6) (2006), 442-444.

[6] M.J. Hasbani, L.H. Sansing, J. Perrone, A.K. Asbury and S.J. Bird, Encephalopathy and peripheral neuropathy following diethylene glycol ingestion, Neurology 64 (1992), 1273-1275.

[7] F. Hernandez, M. Ibanez and J.V. Sancho, Fast determination of toxic diethylene glycol in toothpaste by ultra-performance liquid chromatography - time of flight mass spectrometry, Analytical and Bioanalytical Chemistry 391 (2008), 10211027.

[8] J. Marraffa, M. Holland, C. Stork, C. Hoy and M. Hodgman, Diethylene glycol: widely used solvent presents serious poisoning potential, Journal of Emergency Medicine 35 (2007), 401-406.

[9] H. Maurer and C. Kessler, Identification and quantification of ethylene glycol and diethylene glycol in plasma using gas chromatography-mass spectrometry, Archives of Toxicology 62 (1988), 66-69.

[10] H. Maurer, F.T. Peters, L.D. Paul and T. Kraemer, Validated gas chromatographic - mass spectrometric assay for determination of the antifreezes ethylene glycol and diethylene glycol in human plasma after microwave-assisted pivalylation, Journal of Chromatography B - Biomedical Sciences and Applications 754 (2001), 401-409.

[11] K.L. O'Brien, J.D. Selanikio, C. Hecdivert, M.F. Placide, M. Louis, D.B. Barr et al., Epidemic of pediatric deaths from acute renal failure caused by diethylene glycol poisoning, JAMA 279 (1988), 1175-1180.

[12] H.O. Okuonghae, I.S. Ighogboja, J.O. Lawson and E.J. Nwana, Diethylene glycol poisoning in Nigerian children, Annals of Tropical Paediatrics 12 (1992), 235-238.

[13] L. Schep, R. Slaughter, W. Temple and D. Beasley, Diethylene glycol poisoning, Clinical Toxicology 47(6) (2009), 525535.

[14] J.G. Schier, C.S. Rubin, D.M. Miller, D. Barr and M.A. McGeehin, Medication-associated diethylene glycol mass poisoning: a review and discussion on the origin of contamination, Journal of Public Health 30 (2009), 127-143.

[15] J. Shin, G. Sachs and J. Kraut, Simple diagnostic tests to detect toxic alcohol intoxications, Translational Research 152 (2008), 194-201 


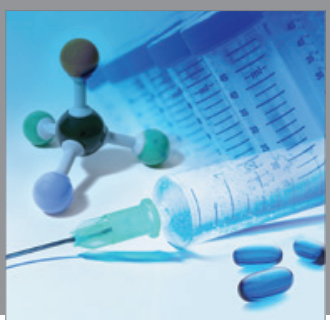

International Journal of

Medicinal Chemistry

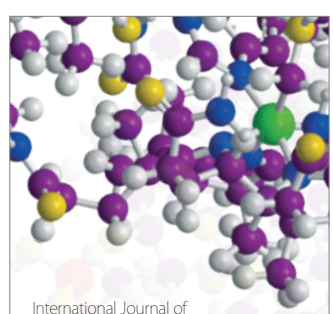

Carbohydrate Chemistry

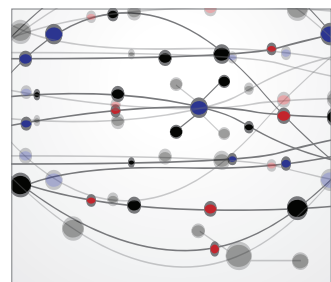

The Scientific World Journal
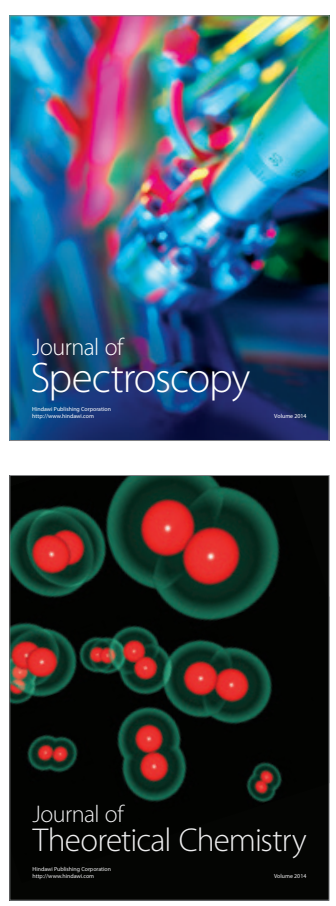
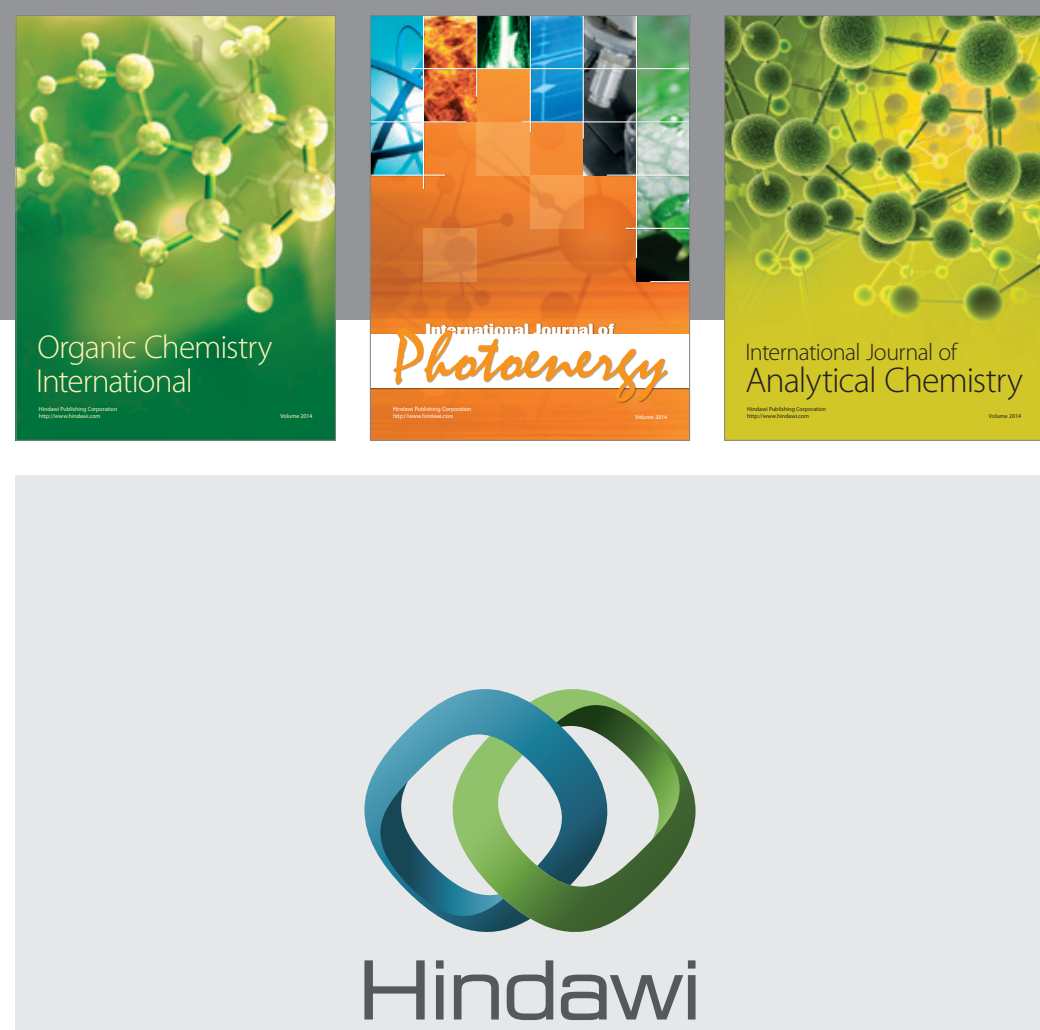

Submit your manuscripts at

http://www.hindawi.com
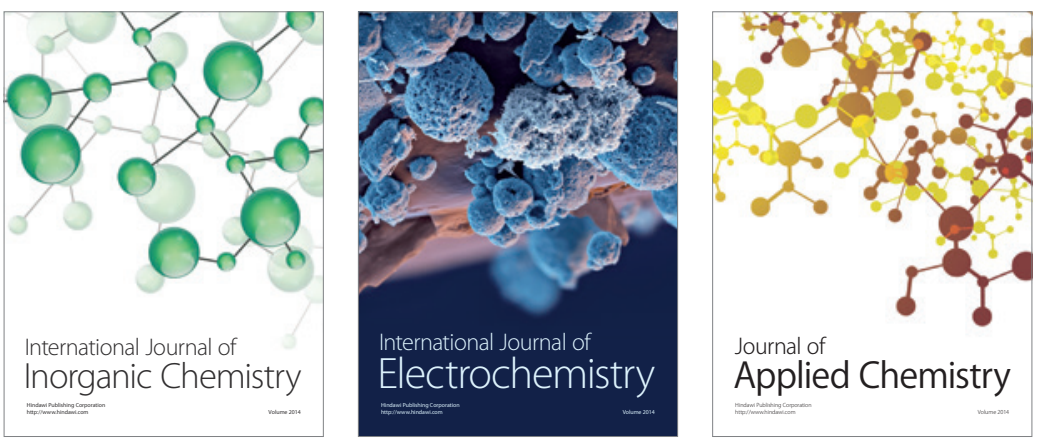

Journal of

Applied Chemistry
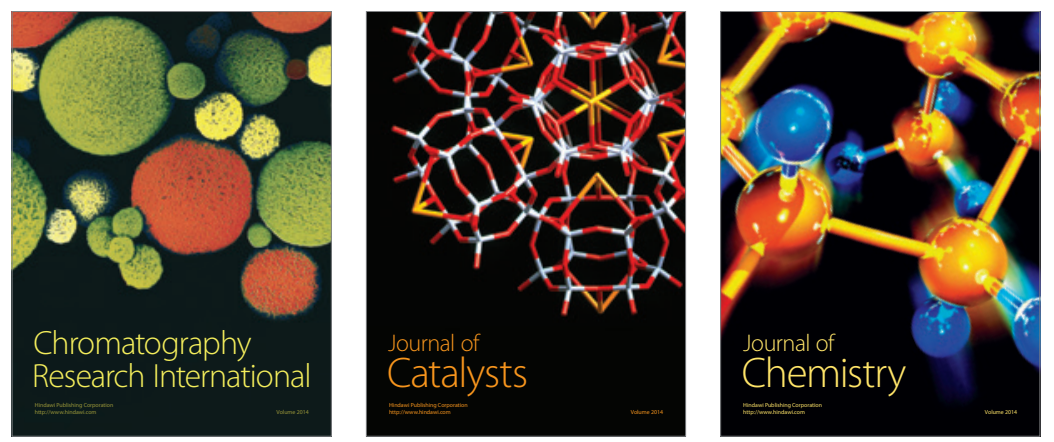
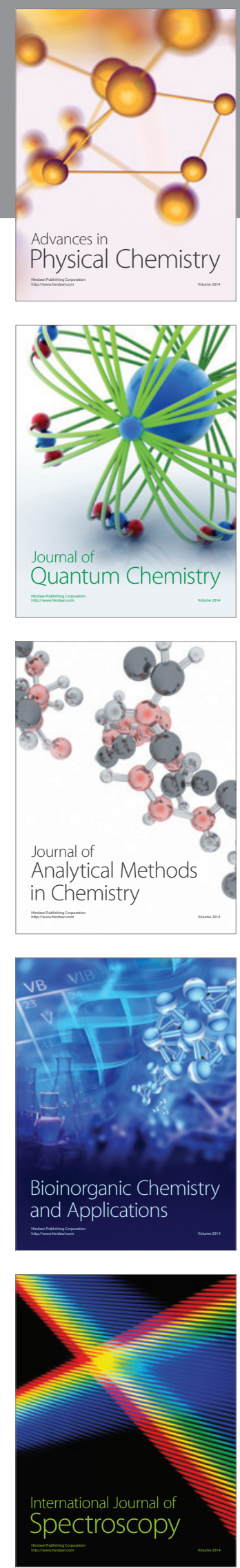